\title{
New Mechanism for Foam Cell Generation in Atherosclerotic Lesions
}

\author{
Linda K. Curtiss, Audrey S. Black, Yasushi Takagi, and Edward F. Plow \\ Department of Immunology, Research Institute of Scripps Clinic, La Jolla, California 92037
}

\begin{abstract}
Because of a close association between platelets and macrophages in early fatty streak lesions, the hypothesis was tested that platelets contribute to lesion progression by directly enhancing macrophage cholesteryl ester (CE) accumulation. Both the rate of cholesterol esterification and the accumulation of $\mathrm{CE}$ were increased within $24 \mathrm{~h}$ of the co-culture of adherent macrophages with platelets. Maximum increases in esterification and CE accumulation were observed within 3 to $4 \mathrm{~d}$ of culture and were $>$ 10-fold over controls. Optimum accumulation of CE by $5 \times 10^{5}$ was obtained with $5 \times 10^{8}$ autologous platelets. When similar amounts of free cholesterol were supplied with platelets, red blood cells (RBC), RBC ghosts, or sonicated RBC, only platelets enhanced macrophage CE accumulation, which indicates specificity for platelets. Products released from platelets $\mathbf{3 0} \mathrm{min}$ after thrombin stimulation were active as well. The results suggest that platelets and/or substances shed by activated platelets are potent mediators of macrophage $\mathrm{CE}$ accumulation.
\end{abstract}

\section{Introduction}

Large numbers of lipid-laden macrophages are the hallmark of early fatty streak lesions (1-3). The mechanisms whereby lipids are sequestered by these cells are not fully understood. Studies of the interaction of plasma-derived lipoproteins with macrophages are pertinent to foam cell formation in areas where the endothelium is intact. However, in areas of endothelial cell injury, other factors may contribute to or accelerate foam cell formation as well. A close association between platelets and monocytes has been documented in areas of endothelial denudation, and this association could enhance macrophage accumulation of cholesteryl esters (CE) ${ }^{1}(1-4)$. As early as 1961 Chandler and Hand (5) suggested that the phagocytosis of lipidrich platelets by macrophages could be a contributing factor to the lipid accumulation observed in foam cells of the more advanced atherosclerotic lesion. Recent studies suggest that activated platelets can contribute at least qualitatively to $\mathrm{CE}$ accumulation in smooth muscle cells (6) and macrophages (7).

In this report we demonstrate that platelets enhance both the rate of $\mathrm{CE}$ formation and the total $\mathrm{CE}$ accumulation in cul-

This is publication No. 4646-IMM from the Dept. of Immunology of the Scripps Clinic.

Received for publication 1 December 1986 and in revised form 25 March 1987.

1. Abbreviations used in this paper: aLDL, acetylated low density lipoprotein; apo E, apoprotein E; CE, cholesteryl esters; PBM, peripheral blood mononuclear cells; RBC, red blood cells.

J. Clin. Invest.

(c) The American Society for Clinical Investigation, Inc.

0021-9738/87/08/0367/07 \$2.00

Volume 80, August 1987, 367-373 tured peripheral blood mononuclear cell (PBM)-derived macrophages. Furthermore, we demonstrate that the capacity of platelets to enhance $\mathrm{CE}$ accumulation is a saturable and specific process and can be induced by products released from activated platelets. It is thus hypothesized that platelets, which accumulate and are activated at sites of vessel wall damage, can enhance the conversion of monocytes into foam cells and thus contribute to the progression of the fatty streak lesion.

\section{Methods}

Lipoproteins. Low density lipoprotein (LDL) was isolated from plasma of normal fasting subjects by sequential ultracentrifugation using $\mathrm{KBr}$ for density adjustment as previously described (8). The LDL was dialyzed against $0.15 \mathrm{M} \mathrm{NaCl}, 0.3 \mathrm{mM}$ EDTA, $5 \mathrm{mM}$ benzamidine, and $0.0005 \%$

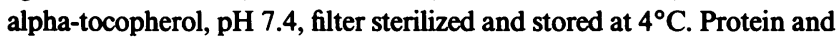
cholesterol were measured by a modification of the method of Lowry using a bovine serum albumin (BSA) standard (9) and by an enzymatic fluorometric assay $(10,11)$, respectively (see below). Apoprotein composition of the lipoproteins was assessed by sodium dodecyl sulfatepolyacrylamide gel electrophoresis (8). Acetylated LDL, modified by treatment of isolated LDL with acetic anhydride, was prepared as described by Basu et al. (12). Acetylation was verified immunochemically with acetyllysine-specific antibodies as described (13).

Isolation of platelets. Platelets were isolated by differential centrifugation from fresh human blood drawn into $5 \mathrm{U} / \mathrm{ml}$ of heparin (14). The heparinized blood was centrifuged at $800 \mathrm{~g}$ for $15 \mathrm{~min}$ at $23^{\circ} \mathrm{C}$ to recover a platelet-rich plasma (PRP) fraction. To minimize platelet activation, prostaglandin $\mathrm{E}_{1}$ and theophylline (Sigma Chemical Co., St. Louis, MO) were added to the PRP at final concentrations of $1 \mu \mathrm{g} / \mathrm{ml}$ and $1 \mathrm{mM}$, respectively. When necessary, the PRP was stored at $22^{\circ} \mathrm{C}$. The platelets were isolated from PRP by centrifugation at $1,000 \mathrm{~g}$ for $20 \mathrm{~min}$, were resuspended in divalent ion free-Tyrode's buffer and washed twice. After the final wash the platelets were resuspended in RPMI 1640, which contained 1\% nutridoma-HU (Boehringer Mannhein Biochemicals, Indianapolis, IN). Platelet supernatants were prepared by activating platelets that were suspended in RPMI 1640 containing $1 \%$ nutridoma-HU at $10^{9}$ cells $/ \mathrm{ml}$, with thrombin at $1 \mathrm{U} / \mathrm{ml}$ in the presence of $1 \mathrm{mM} \mathrm{CaCl}$. After $3 \mathrm{~h}$ at $37^{\circ} \mathrm{C}$ platelet pellets and platelet supernatants were recovered by centrifugation at $1,000 \mathrm{~g}$ for $20 \mathrm{~min}$. When necessary, the platelet supernatants were stored at $4^{\circ} \mathrm{C}$. Platelet protein and cholesterol were measured as described above.

When platelet serotonin secretion was measured, the platelets were prelabeled with 5-hydroxy[G- $\left.{ }^{3} \mathrm{H}\right]$ tryptamine creatinine sulfate and its secretion assayed in the presence of $2 \mu \mathrm{M}$ imipramine as described (15). The secretion of platelet beta thromboglobulin was assayed with an immunoassay kit supplied by Amersham Corp. (Arlington Heights, IL). For these analyses, the platelet supernatants were collected by centrifugation of the cell suspension for $3 \mathrm{~min}$ in a Beckman microfuge.

Isolation of PBM and red blood cells $(R B C)$. PBM were isolated from heparinized blood by differential centrifugation (16). After removal of the PRP, the cell pellet was resuspended to two times its original volume in RPMI 1640 that contained $10 \mathrm{mM}$ Hepes, $2 \mathrm{mM}$ glutamine, 0.05 $\mathrm{mg} / \mathrm{ml}$ gentamicin, and $1 \mathrm{mM}$ sodium pyruvate. The resuspended cells were layered onto Ficoll-Hypaque and centrifuged at $1,000 \mathrm{~g}$ for $20 \mathrm{~min}$. Cells at the interface were removed, washed, and resuspended in RPMI 1640 that contained 1\% Nutridoma-HU. The PBM cells were adjusted to a concentration of $5 \times 10^{6} / \mathrm{ml}$, and $1.0-\mathrm{ml}$ cultures established in 12 well, $22-\mathrm{mm}$ diam plastic culture plates. After incubation at $37^{\circ} \mathrm{C}$ for 
$24 \mathrm{~h}$, nonadherent cells were removed by washing the wells three times and the adherent cells fed again with RPMI 1640 that contained 1\% nutridoma-HU. This adherent cell population contained $>96 \%$ esterasepositive cells and represented between 5 and $15 \%$ of the $5 \times 10^{6} \mathrm{PBM}$. Platelet contamination as assessed visually averaged between zero and four platelets per adherent cell. The adherent cells were cultured at a final volume of $1.0 \mathrm{ml}$ in the presence of added lipoproteins or platelets as indicated.

RBC were obtained from the Ficoll-Hypaque pellet and washed repeatedly in RPMI 1640. RBC ghosts were obtained by lysing the cells in $\mathrm{H}_{2} \mathrm{O}$ and recovering the ghosts by centrifugation at $39,200 \mathrm{~g}$. A portion of the RBC ghosts also were sonicated for $10 \mathrm{~min}$ at $20 \mathrm{~W}$ in RPMI 1640. Visual inspection of the sonicate revealed the absence of intact ghosts. A comparison of the size of the sonicated RBC ghosts, as monitored by the presence of free cholesterol, indicated that $>70 \%$ of the cholesterol could be passed through a $0.45 \mu \mathrm{m}$ sterile filter, but $99 \%$ was retained on a XM300 Diaflo ultrafiltration membrane (Amicon Corp., Lexington, MA) consistent with a molecular weight of the sonicated ghosts exceeding 300,000 . Furthermore, the cholesterol associated with the sonicates eluted in the void volume of a Sepharose CL-2B column (Pharmacia Fine Chemicals, Piscataway, NJ). Opsonized RBC were prepared by incubating the cells with an optimum concentration of rabbit anti-erythrocyte antibody. Binding of the opsonized RBC to the monocytes was verified by light microscopy. Most macrophages contained $>10$ adherent $\mathrm{RBC}$.

Cell harvest. $2 \mathrm{~h}$ before harvest, $\left[{ }^{3} \mathrm{H}\right]$ oleate (New England Nuclear, Boston, MA) was added at a final concentration of $200 \mu \mathrm{M}$ oleate. The $\left[{ }^{3} \mathrm{H}\right.$ ]oleate had a specific activity of $25 \mathrm{mCi} / \mathrm{mM}$ and was added as a 4.5: 1 (oleate/albumin) molar complex. The cells were harvested by transferring the supernatants to $1.2-\mathrm{ml}$ microfuge tubes (Brinkman Instruments Inc., Westbury, NY) that were spun at $8,000 \mathrm{~g}$ for $2.5 \mathrm{~min}$ in a Beckman Microfuge II. The clarified supernatants were stored at $-20^{\circ} \mathrm{C}$ for assay of apoprotein E (apo E) by radioimmunoassay as described below. The adherent cells were washed twice with cold phosphate-buffered saline and extracted with $1 \mathrm{ml}$ of absolute ethanol. The cells were scraped from the wells and added to the original cell debris recovered above, and were pelleted by centrifugation at $8,000 \mathrm{~g}$ for $2.5 \mathrm{~min}$ in a microfuge. The soluble ethanol extracts were transferred to $12 \times 75-\mathrm{mm}$ glass tubes and evaporated to dryness in a Speedvac concentrator (Savant Instruments Inc., Hicksville, NY) for counting and for assay of cholesterol. The cells and debris recovered in the pellets were retained for assay of DNA as described below. Although only the macrophages contained detectable amounts of either CE or DNA, this harvesting procedure resulted in the collection of all adherent or nonadherent cells and debris (platelet, RBC, and macrophage) for subsequent assay.

Apo $E$ secretion. Apo $\mathrm{E}$ in the culture medium was assayed immunochemically in a sensitive competitive solid-phase radioimmunoassay. Microtiter plates were precoated with $0.1 \mathrm{ml}$ of protein A at $500 \mathrm{ng} / \mathrm{ml}$ in borate-buffered saline and then coated with the apo E-specific monoclonal antibody, $1 \mathrm{E}$ (17). The $1 \mathrm{E}$ antibody is an IgG2a $\mathrm{k}$ antibody, which was generated from the fusion of P3.Ag8.653.1 myeloma cells with the spleen cells of a BALB/c mouse immunized with isolated apo E. All antibodies, competitors, and standards were diluted with borate-buffered saline that contained 3\% BSA and $4 \mathrm{mM} N$-octyl-beta-D-glucopyranoside. Monocyte culture supernatants or standards $(0.1 \mathrm{ml})$ were added to the antibody-coated wells. The plates were incubated at $4^{\circ} \mathrm{C}$ for $18 \mathrm{~h}$ and washed extensively. Apo E was quantitated with a second 3-h incubation at $4^{\circ} \mathrm{C}$ with $0.1 \mathrm{ml}$ of ${ }^{125} \mathrm{I}$-apo $\mathrm{E}$. Apo $\mathrm{E}$ was radioiodinated to specific activities of 7-12 $\mu \mathrm{Ci} / \mu \mathrm{g}$ as described (18) and $200,000 \mathrm{cpm}$ added per well. A specificity control was included in each assay in which an irrelevant antibody of the same heavy chain class was substituted for $1 \mathrm{E}$. Data was expressed as $B / B_{0}$, with $B$ representing the amount bound in the presence and $B_{0}$ the amount bound in the absence of competitors. The apo $E$ standard was isolated as described (18) and its protein content was estimated with the modified Lowry assay (9).

$C E$ formation and accumulation. Cholesterol esterification was measured as incorporation of $\left[{ }^{3} \mathrm{H}\right]$ oleate into $\mathrm{CE}$ during the final $2 \mathrm{~h}$ of culture. CE in ethanol extracts of cells were separated by chromatography on disposable aminopropyl bonded-phase columns (Bond Elute; Analytichem International, Harbor City, CA) as described (19). For chromatography the dried ethanol extracts were resuspended in $1.5 \mathrm{ml}$ of hexane and applied to the column. CE were eluted under vacuum with $4 \mathrm{ml}$ of hexane. The free cholesterol retained on the column was eluted with $20 \mathrm{ml}$ of $15 \%$ ethyl acetate. The separate hexane and ethyl acetate extracts were dried in the presence of $\mathrm{N}_{2}$, were resuspended in $0.2 \mathrm{ml}$ of absolute ethanol, and $0.015-\mathrm{ml}$ aliquots were transferred to glass tubes for measurement of total cholesterol as described below. The remaining $0.1 \mathrm{ml}$ was counted in the presence of $4 \mathrm{ml}$ of $3 \mathrm{a}_{20}$ (Research Products International Corp., Mt. Prospect, IL). Results were expressed as picomoles of $\left[{ }^{3} \mathrm{H}\right]$ oleate incorporated in $2 \mathrm{~h}$ into cholesteryl $\left[{ }^{3} \mathrm{H}\right]$ oleate per microgram of cellular DNA and were corrected for recovery. Recovery was estimated by the addition of $\left[{ }^{14} \mathrm{C}\right]$ cholesteryl oleate to the ethanol extracts before chromatography and it ranged from 50 to $100 \%$.

Cholesterol and CE mass were measured by the fluorometric enzymatic methods of Gamble et al. (10), and Heider and Boyit (11). For assay the CE were hydrolyzed with cholesteryl ester hydrolase (Boehringer-Mannheim Biochemicals, Indianapolis, IN). Results were expressed as nanograms of cholesterol per microgram of cellular DNA.

Cellular DNA. DNA content of the cell pellets was measured with a diphenylamine assay (20). Cell debris, recovered after ethanol extraction, was resuspended in $0.3 \mathrm{ml}$ of $\mathrm{H}_{2} \mathrm{O}$ and digested for $5 \mathrm{~min}$ at $90^{\circ} \mathrm{C}$ with perchloric acid. After a 24-h incubation with diphenylamine and acetylaldehyde the absorbance was monitored at $620 \mathrm{~nm}$ and converted to micrograms of DNA by reference to a standard curve prepared with calf thymus DNA (Sigma Chemical Co., St. Louis, MO). Between 5 and 7 $\mu \mathrm{g}$ of DNA was recovered per 1.0-ml culture, which contained 5-7 $\times 10^{5}$ adherent cells. Platelets contained $<1.0 \mu \mathrm{g}$ of DNA $/ 10^{9}$ cells.

Cellular protein synthesis. Protein synthesis in the cultured macrophages was measured by assessing the incorporation of $\left[{ }^{3} \mathrm{H}\right]$ leucine into trichloracetic acid (TCA) precipitable counts. 1-ml cultures were established in serum-free medium as described above and incubated with 5 $\times 10^{8}$ whole platelets, $10^{9}$ sonicated $R B C$, the 5-min supernatants of $10^{9}$ thrombin-stimulated platelets, or the 3-h supernatants of $10^{9}$ thrombinstimulated platelets. After $48 \mathrm{~h}$ of culture the cells were washed and resuspended in $0.5 \mathrm{ml}$ of leucine-free RPMI 1640 containing $1 \mu \mathrm{Ci}$ of $\left[{ }^{3} \mathrm{H}\right]$ leucine $(50 \mathrm{Ci} / \mathrm{mmole})$. The cells were harvested after a 2 -h pulse and the proteins precipitated with $10 \%$ TCA.

\section{Results}

The capacity of platelets to enhance $\mathrm{CE}$ accumulation in cultured human macrophages was first observed in experiments performed to identify factors that could increase the production and secretion of apo E. Peripheral blood mononuclear adherent cells were cultured for $6 \mathrm{~d}$ in serum-free medium in the presence of a variety of factors including: $100 \mu \mathrm{g} / \mathrm{ml}$ of LDL, $100 \mu \mathrm{g} / \mathrm{ml}$ of acetylated LDL (aLDL), $360 \mu \mathrm{g} / \mathrm{ml}$ of urate crystals, $10 \mu \mathrm{g} /$ $\mathrm{ml}$ of lipopolysaccharide (LPS), and $10^{9} / \mathrm{ml}$ of isolated autologous platelets (Fig. 1). As reported previously for mouse peritoneal macrophages and human monocyte-derived macrophages $(12,21,22)$, aLDL enhanced the production and secretion of apo $\mathrm{E}$ by these cultured cells (Fig. $1 \mathrm{~A}$ ). However, the increase in apo $\mathrm{E}$ production induced by the culture of macrophages in the presence of platelets exceeded that obtained with aLDL. In these same cells, stimuli such as urate crystals or LPS reduced apo $\mathrm{E}$ production below control levels obtained with only medium.

To determine if the enhancement of apo $E$ production observed with platelets was a reflection of their capacity to increase $\mathrm{CE}$ accumulation in these cells, the macrophages were extracted into ethanol and the total amount of accumulated CE was measured (Fig. $1 B$ ). The enhanced apo $E$ production paralleled an increase in the CE content of the cultured macrophages. (Platelets 

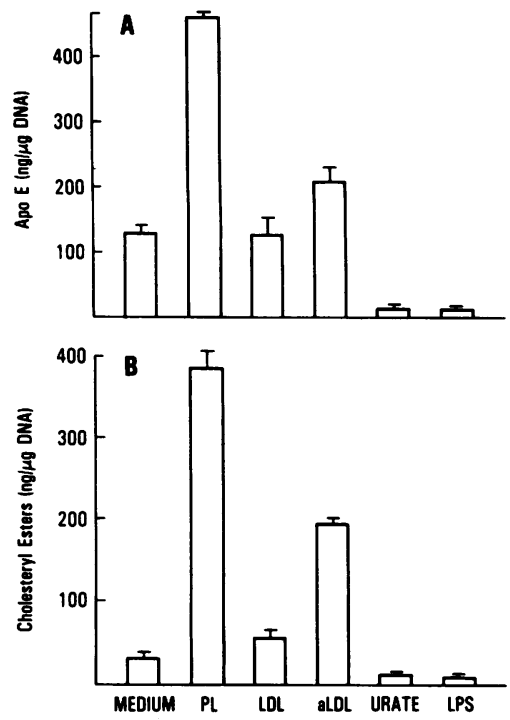

supernatants, and the cells harvested for assay of CE and DNA.

cultured in the absence of macrophages contained no detectable apo $\mathrm{E}$ or $\mathrm{CE}$ and $<1 \mu \mathrm{g}$ of DNA $/ 10^{9}$ platelets.) By culture with $10^{9}$ autologous platelets containing $\sim 42 \mu \mathrm{g}$ of free cholesterol, these human monocyte-derived macrophages contained almost $400 \mathrm{ng}$ of $\mathrm{CE} / \mu \mathrm{g}$ of cellular DNA.

The role of platelet activation in enhancing $\mathrm{CE}$ accumulation by macrophages was investigated. Isolated platelets were incubated for $1 \mathrm{~h}$ in the presence or absence of $1 \mathrm{U} / \mathrm{ml}$ of $\alpha$-thrombin. The reaction mixtures were then centrifuged at $1,000 \mathrm{~g}$ for 20 min to obtain platelet pellet and supernatant fractions. Resuspended platelets were obtained by immediately resuspending the pelleted platelets. These fractions were then added to the adherent cell cultures. After $7 \mathrm{~d}$, the incorporation of $\left[{ }^{3} \mathrm{H}\right]$ oleate into $C E$ was the same for cells cultured with resuspended platelets or platelet pellets, irrespective of thrombin activation (Fig. 2). This suggested that stimulation was not required when resuspended platelets or platelet pellets (debris) were used. However, differences were observed between unstimulated and thrombinstimulated platelets when only the $1,000-\mathrm{g}$ supernatants were added to the macrophage cultures. The supernatants of stimulated platelets enhanced CE accumulation, whereas the supernatants of unstimulated platelets were not active. Thus, only thrombin-stimulated platelets released a substance(s) that enhanced cholesterol esterification (Fig. 2), but either stimulated or unstimulated platelet pellets were active by themselves.

To determine if the capacity of platelets to enhance CE accumulation in cultured macrophages was specific to platelets, RBC were tested for their capacity to facilitate $C E$ accumulation. The capacity of $10^{9}$ platelets to enhance CE accumulation was compared with the capacity of $10^{9} \mathrm{RBC}$ or RBC ghosts (Fig. 3). Only platelets were capable of facilitating cholesterol loading of these cells despite the fact that comparable amounts of free cholesterol were added to the macrophages with each cell type. In additional studies it was determined that $10^{9} \mathrm{RBC}$ opsonized with rabbit antibody or sonicated RBC ghosts were devoid of activity as well (Table I). The opsonized RBC were tested to determine if close cell/cell contact would facilitate macrophage CE accumulation, whereas the sonicated RBC ghosts were tested to determine if smaller cholesterol-rich vesicles were more easily

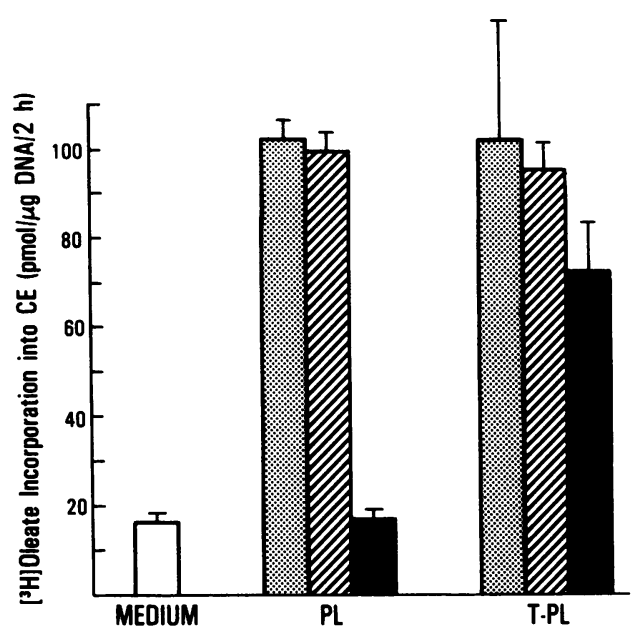

Figure 2. Effect of platelet stimulation on $\left[{ }^{3} \mathrm{H}\right]$ oleate incorporation into cholesteryl $\left[{ }^{3} \mathrm{H}\right]$ oleate. Platelets were prepared by isolating them from plasma and incubating them in RPMI 1640 for $1 \mathrm{~h}$ at $37^{\circ} \mathrm{C}$ in the presence (T-PL) or absence (PL) of $1 \mathrm{U} / \mathrm{ml}$ of $\alpha$-thrombin. The incubated platelets were then pelleted by centrifugation at $1,000 \mathrm{~g}$. Resuspended platelets were obtained by remixing the entire reaction mixtures. Resuspended platelets $(\square)$, platelet pellets $(\square)$, or platelet supernatants $(\square)$ were added separately to the adherent cells from $5 \times 10^{6}$ PBM and the cultures incubated at $37^{\circ} \mathrm{C}$. After $7 \mathrm{~d}$ the rate of cholesterol esterification was measured by measuring the incorporation of $\left[{ }^{14} \mathrm{C}\right]$ oleate into cholesteryl $\left[{ }^{3} \mathrm{H}\right]$ oleate.

phagocytozed. The results suggest that an interaction specific to platelets was required. The size of the cholesterol-rich fraction of the thrombin-stimulated platelet supernatants and the cholesterol-rich sonicated $R B C$ vesicles were similar, as both could

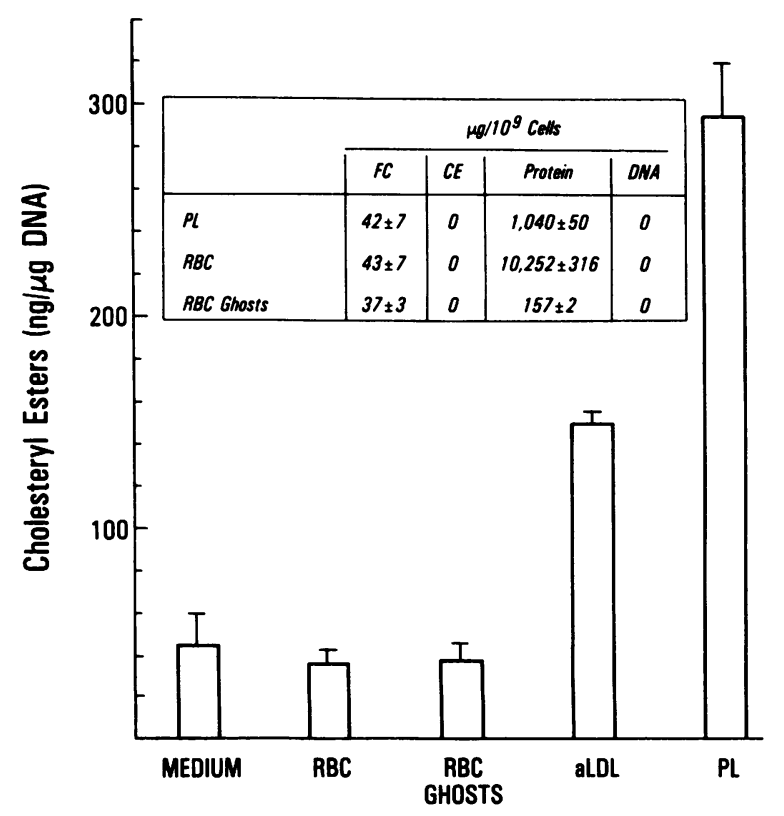

Figure 3. Specificity of platelet-induced CE accumulation. The adherent cells from $5 \times 10^{6} \mathrm{PBM}$ were cultured in the presence of medium, $10^{9}$ intact $\mathrm{RBC}, 10^{9} \mathrm{RBC}$ ghosts, $100 \mu \mathrm{g}$ of aLDL, or $10^{9}$ unstimulated whole platelets. Macrophage $\mathrm{CE}$ accumulation was measured on day 6. The free cholesterol (FC), CE, protein, and DNA content of $10^{9}$ platelets, $R B C$, and $R B C$ ghosts are shown. 
Table I. Specificity of Platelet-induced CE

\begin{tabular}{lc}
\hline & $\mathrm{CE}^{*}$ \\
\hline & $n g / \mu g$ DNA \\
Macrophages incubated with: & \\
Medium & $10 \pm 2$ \\
Platelet supernatant $\left(10^{9}\right)^{\ddagger}$ & $279 \pm 32$ \\
RBC $\left(10^{9}\right)$ & $8 \pm 3$ \\
Opsonized RBC $\left(10^{9}\right)^{8}$ & $12 \pm 4$ \\
Sonicated RBC $\left(10^{9}\right)$ & $22 \pm 7$ \\
\hline
\end{tabular}

* CE accumulation was measured on day 3.

$\$ 10^{9}$ platelets were incubated with $1 \mathrm{U} / \mathrm{ml}$ of thrombin and $1 \mathrm{mM}$ $\mathrm{CaCl}_{2}$ for $3 \mathrm{~h}$ at $37^{\circ} \mathrm{C}$ and the supernatant recovered by centrifugation at $8,000 \mathrm{~g}$ for $3 \mathrm{~min}$.

$10^{9} \mathrm{RBC}$ were incubated with a 1:200 dilution of rabbit anti-human erythrocyte membrane antiserum for $30 \mathrm{~min}$ and washed.

be filtered through a $0.45-\mu \mathrm{m}$ sterile filter but were retained on a 300,000- $M_{\mathrm{r}}$ membrane filter. Similarly, the cholesterol of either fraction was recovered in the void volume of a Sepharose CL2B molecular sieve column, suggesting that the cholesterol-rich vesicles were very large.

To further characterize the effect of platelets on macrophage $\mathrm{CE}$ accumulation, we measured the kinetics of oleate incorporation into cholesteryl oleate as well as the total mass of cellular CE. Whereas the rate of incorporation of $\left[{ }^{3} \mathrm{H}\right]$ oleate into CE by control cells gradually increased from 12 to $44 \mathrm{pmol} / \mu \mathrm{g}$ DNA between 0 and $6 \mathrm{~d}$ of culture, the incorporation by cells cultured with $10^{9}$ platelets was maximal at $200 \mathrm{pmol} / \mu \mathrm{g}$ DNA by $3 \mathrm{~d}$ of culture and then declined to $70 \mathrm{pmol} / \mu \mathrm{g}$ DNA by the 6 th $\mathrm{d}$ of culture (Fig. $4 \mathrm{~A}$ ). These changes in the rate of cholesteryl $\left[{ }^{3} \mathrm{H}\right]$ oleate formation were reflected in similar measurements of total CE accumulation. Within $2 \mathrm{~d},>100 \mathrm{ng}$ of CE were detected per microgram of cellular DNA. This accumulation was maximal by day 3 and was maintained for at least $6 \mathrm{~d}$ of culture (Fig. 4 $B)$. Therefore, cells cultured in serum-free medium in the presence of platelets demonstrated a dramatic increase in the rate
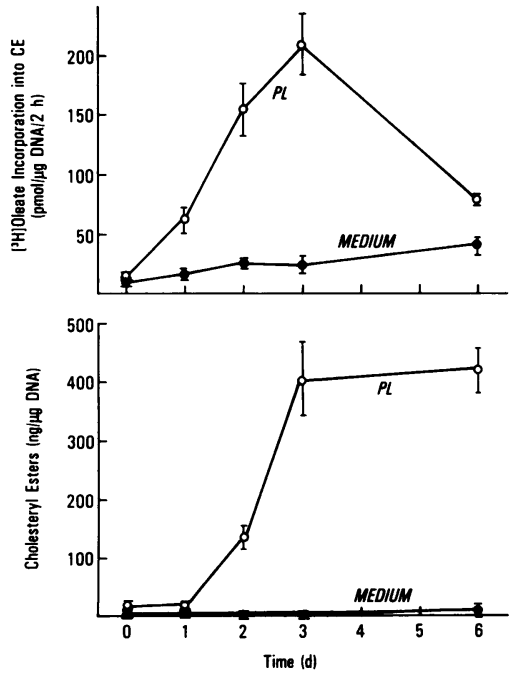

Figure 4. Effects of platelets on the kinetics of macrophage oleate incorporation into cholesteryl oleate and the total cellular accumulation of esterified cholesterol. The adherent cells from $5 \times 10^{6} \mathrm{PBM}$ were cultured in $1.0 \mathrm{ml}$ of control medium with or without $10^{9}$ autologous unstimulated platelets. At the times indicated, the cells were pulsed with $\left[{ }^{3} \mathrm{H}\right]$ oleate, and $2 \mathrm{~h}$ later the cells were harvested and extracted into ethanol for estimation of cholesterol esteri-

fication and $\mathrm{CE}$ accumulation. Cell yield was estimated by measuring the recovery of cellular DNA. of cholesterol esterification, which was reflected also in a large increase in the $\mathrm{CE}$ content of these cells. Furthermore, by day 3 of culture morphologic examination of these platelet-cultured cells by light microscopy demonstrated the presence of numerous lipid droplets that were easily visualized in virtually all macrophages, giving them the appearance of typical foam cells. Most of the macrophages also had platelets adhering to their surface.

To determine the optimum number of platelets for macrophage cholesterol loading, increasing numbers of platelets were added to $1.0-\mathrm{ml}$ cultures that contained $\sim 5 \times 10^{5}$ adherent cells. After $48 \mathrm{~h}$ both the rate of cholesterol esterification and the total amount of accumulated CE were measured (Fig. 5). Maximum rates of $\left[{ }^{3} \mathrm{H}\right]$ oleate incorporation into cholesteryl oleate were obtained with $2.5-5 \times 10^{8}$ platelets $/ \mathrm{ml}$, and minimal rates were obtained with $<2 \times 10^{7}$ or $>2 \times 10^{9}$ platelets $/ \mathrm{ml}$. Similar relationships were observed when the CE mass was measured after $48 \mathrm{~h}$ of culture. Maximal CE accumulation was observed with $5 \times 10^{8}$ platelets $/ \mathrm{ml}$ and was minimal at $<2 \times 10^{7}$ or $>2 \times 10^{9} / \mathrm{ml}$.

To more carefully characterize the supernatants of thrombinstimulated platelets that induced CE formation (Fig. 2), isolated platelets were adjusted to a concentration of $10^{9} / \mathrm{ml}$ in Tyrode's buffer and exposed to $\alpha$-thrombin. At varying times the reaction mixtures were spun at $10,000 \mathrm{~g}$ for $3 \mathrm{~min}$ in a Beckman microfuge and the supernatants monitored for their capacity to induce macrophage GE accumulation. As shown in Fig. 6, the biologic activity of the platelet supernatants (as assessed by their capacity to induce $\mathrm{CE}$ accumulation in cultured macrophages assayed on day 3) increased between 0 and $60 \mathrm{~min}$ after platelet stimulation. The platelet supernatants obtained after $30 \mathrm{~min}$ of thrombin stimulation induced the accumulation on day 3 of $124 \pm 12 \mathrm{ng}$ of esterified cholesterol per microgram of macrophage DNA compared with the platelet supernatants obtained after 10 min of thrombin stimulation. These 10 -min supernatants induced the accumulation on day 3 of only $34 \pm 15 \mathrm{ng}$ of esterified cholesterol per microgram of macrophage DNA.

This time scale for release of biologic activity appeared to be prolonged relative to the platelet secretory reaction. Therefore, these same platelet supernatants were monitored for specific platelet constituents including serotonin, a platelet dense granule marker, $\beta$-thromboglobulin, an alpha granule marker, as well as for free cholesterol, a membrane marker. Thrombin-induced

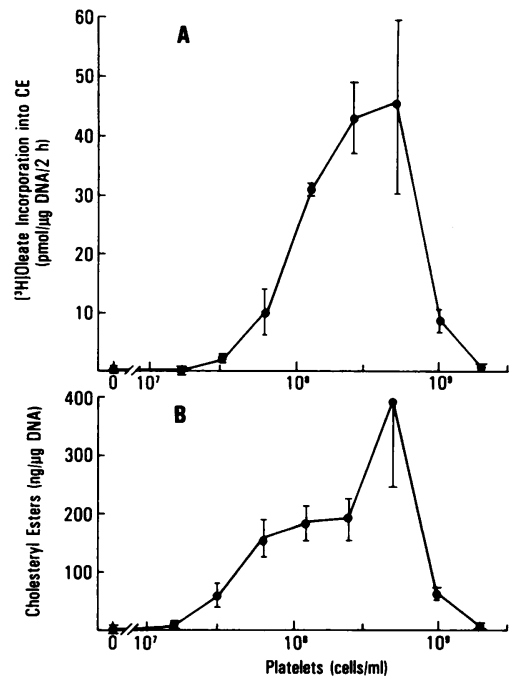

Figure 5. Effect of platelet dose on macrophage cholesterol esterification and $\mathrm{CE}$ accumulation. The adherent cells from $5 \times 10^{6}$ PBM were cultured in the presence of medium or increasing numbers of autologous unstimulated platelets. After $2 \mathrm{~d}$ the cells were pulsed with $\left[{ }^{3} \mathrm{H}\right]$ oleate and harvested $2 \mathrm{~h}$ later for estimations of the rate of cholesterol esterification, CE accumulation, and cellular DNA. 


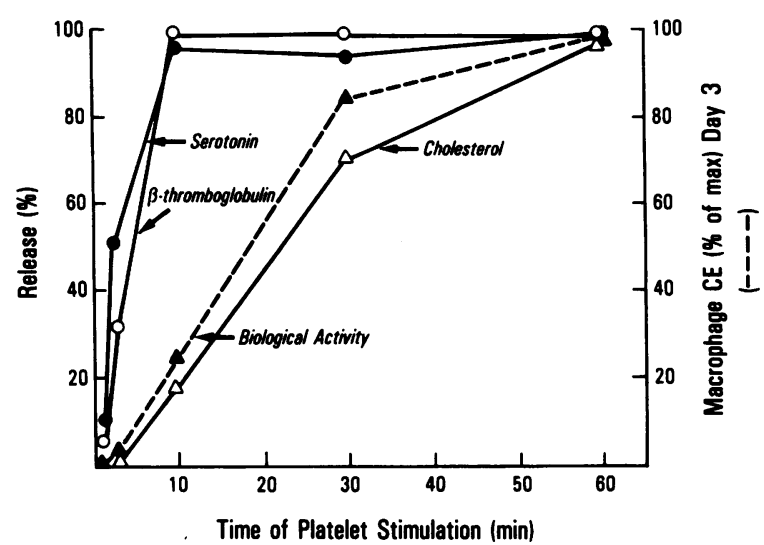

Figure 6. Macrophage CE accumulation by thrombin-stimulated platelet supernatants:correlation with platelet-free cholesterol. Isolated platelets were adjusted to $10^{9} / \mathrm{ml}$ in RPMI 1640 . The platelets were incubated at $37^{\circ} \mathrm{C}$ in the presence of $1 \mathrm{U} / \mathrm{ml}$ of $\alpha$-thrombin plus $1 \mathrm{mM}$ $\mathrm{CaCl}_{2}$. At the times indicated the reaction mixtures were centrifuged at $10,000 \mathrm{~g}$ for $3 \mathrm{~min}$, and the supernatants collected for assay of serotonin, $\beta$-thromboglobulin, free cholesterol, and biological activity. For estimates of percent release for serotonin, $\beta$-thromboglobulin, and cholesterol (solid lines), maximum release was taken as the value at 60 $\min$. For serotonin and $\beta$-thromboglobulin this represented $\geq 95 \%$ of the total platelet content of these constituents. For cholesterol this represented only $16 \%$ of the total platelet cholesterol; however, the amount released at 60 min appeared to represent $100 \%$ of the maximum releasable cholesterol because the 120 -min supernatants also contained only $16 \%$ of the total platelet cholesterol. Biological activity expressed as percent of maximum (dashed line) was measured by assaying the capacity of the supernatants to induce the accumulation of $\mathrm{CE}$. The adherent cells from $5 \times 10^{6} \mathrm{PBM}$ were cultured for $3 \mathrm{~d}$ in the presence of $1 \mathrm{ml}$ of platelet supernatant. Maximum biological activity was taken also as the value at $60 \mathrm{~min}$, which was $135 \pm 22 \mathrm{ng} \mathrm{CE} / \mu \mathrm{g}$ of macrophage DNA.

serotonin and $\beta$-thromboglobulin secretion were $\geq 90 \%$ complete by $10 \mathrm{~min}$, whereas the recovery of cholesterol was $\leq 30 \%$ of the maximum response by $10 \mathrm{~min}$. This suggested that the released cholesterol was not a typical platelet dense granule or $\alpha$-granule secretion product. More importantly, only the platelet supernatants that contained cholesterol were capable of enhancing macrophage accumulation of $\mathrm{CE}$, and a direct correlation was found between the biologic activity of platelet supernatants and their content of free cholesterol $(r=0.98)$.

To verify that the enhanced esterification rates and $\mathrm{CE}$ accumulation observed in platelet-exposed macrophages did not reflect just differences in cellular rates of protein synthesis, a biologically inactive 5-min platelet supernatant was compared with a biologically active 3-h platelet supernatant for their capacity to support cellular protein synthesis. Protein synthesis was assessed by measuring the incorporation of $\left[{ }^{3} \mathrm{H}\right] l$ leucine into TCA precipitable radioactivity. After a 2-h pulse with $\left[{ }^{3} \mathrm{H}\right]$ leucine, macrophages cultured for $24 \mathrm{~h}$ with $5 \times 10^{8}$ platelets, the 5-min supernatants from $10^{9}$ thrombin-stimulated platelets, or the 3-h supernatants of thrombin-stimulated platelets contained $1,508 \pm 35,1,457 \pm 116$, and $1,802 \pm 78$ TCA precipitable counts per microgram DNA, respectively. In additional experiments, no differences were observed in the rates of protein synthesis in macrophages cultured with platelets or sonicated RBC ghosts, although again large differences were observed in the capacity of the platelets or RBC to induce CE accumulation
(Table I). The results provided additional evidence that platelets and/or substances released by activated platelets specifically enhanced macrophage $\mathrm{CE}$ accumulation.

\section{Discussion}

Our understanding of the role macrophages play in cholesterol metabolism has increased significantly over the past few years. Macrophages can take up and degrade numerous cholesterolcontaining substances including cell debris and plasma lipoproteins. A great deal of work has been done to describe the capacity of macrophages to bind and degrade specifically modified or cholesterol-rich lipoproteins (23). The cellular uptake of these lipoproteins leads to the hydrolysis of lysosomal CE that results in the release of intracellular free cholesterol, which is esterified by the microsomal acyl-CoA:cholesterol acyltransferase (ACAT) system and stored internally as lipid droplets. Macrophages that contain large amounts of stored $\mathrm{CE}$ also increase their synthesis of a specific apolipoprotein, apo E (12). In our studies of factors that influenced the production of apo $\mathrm{E}$ by cultured human monocytes, different means of loading the cells with $\mathrm{CE}$ were sought. As expected, the modified lipoprotein, aLDL, enhanced CE storage and stimulated an increase in apo $\mathrm{E}$ production. As described by Kayden et al. (22), native LDL was active as well, although the degree of $\mathrm{CE}$ accumulation and subsequent apo $\mathrm{E}$ production was considerably less. Similarly, it was reported that apo E production is decreased (24) when monocyte/macrophages are cultured in the presence of specific stimuli such as endotoxin. These observations were confirmed here, where it was demonstrated that LPS and urate crystals inhibited both CE accumulation and apo E production. To provide another source of cholesterol for macrophage $\mathrm{CE}$ accumulation, autologous unstimulated platelets were added to the cultured macrophages. The result was a striking increase in macrophage $C E$ to a level that exceeded the level obtained with acetylated LDL.

Although "foam cell formation" typically implies that the intracellular ratio of esterified cholesterol to free cholesterol approaches or exceeds $>50 \%$ of total cellular cholesterol, this ratio could not be accurately measured in these studies because of the contribution of the activated platelets (or opsonized RBC) to the free cholesterol content of the harvested cells. Upon microscopic examination, a close association was always observed between the activated platelet (or opsonized RBC) and macrophages, indicating that the estimates of macrophage free cholesterol and protein reflected platelet-associated free cholesterol and protein as well. Therefore, all of these studies report only rates of cholesterol esterification or CE mass and were corrected for cell recovery on the basis of DNA rather than protein.

The kinetics of platelet-induced cholesterol esterification and $\mathrm{CE}$ accumulation were similar in that maximum rates of esterification and maximum accumulation were observed within 2 to $3 \mathrm{~d}$ of culture. Furthermore, the optimum platelet doses for macrophage cholesterol esterification and $\mathrm{CE}$ accumulation were comparable and were within a physiologically significant ratio of platelets to monocytes.

To understand if the capacity of platelets to enhance macrophage cholesterol esterification was specific to platelets, comparable amounts of free cholesterol in the form of $\mathrm{RBC}, \mathrm{RBC}$ ghosts, sonicated RBC ghosts, or opsonized RBC were co-cultured with macrophages. All of these supported comparable levels of protein synthesis, yet only platelets enhanced CE accumu- 
lation, suggesting that a specific interaction between monocytes and platelets may be required for this phenomenon to occur. Selective binding of activated platelets to human monocytes has been described (25), and this could imply that specific adhesive proteins and their receptors facilitate this interaction.

The requirement for platelet activation also was investigated. In early experiments no specific platelet stimuli were used. Because no particular precautions were taken in these experiments to prevent platelet stimulation, it is highly probable that the platelets were activated. When a specific requirement for platelet stimulation was investigated, it was found. That is, the supernatants of unstimulated platelets were not active, whereas the supernatants from thrombin-stimulated platelets were active. Because only platelet supernatants that contained cholesterol were active, it implies that free cholesterol may be required for activity. However, at this point only a correlation exists between free cholesterol and activity and requirements for other factors or substances cannot be ruled out. The observation that cholesterol-containing sonicates of RBC ghosts were not active suggests that if free cholesterol is involved, its association with other platelet constituents may be crucial for its activity.

As shown in Fig. 5, declines in both the formation and mass of $\mathrm{CE}$ were observed with high concentrations of platelets. Because the cell recovery as assessed by the recovery of DNA was the same in cultures containing large numbers of platelets, other explanations must be sought for the decline in activity. Perhaps factors that competitively inhibit CE accumulation were produced at the higher platelet concentrations. These inhibitory factors could be related to the platelet secretory factors described recently by Phillips et al. (26). These investigators reported that the supernatants of thrombin-stimulated platelets inhibited macrophage $C E$ accumulation that resulted from culture in the presence of aLDL. It was concluded that the platelet supernatants contained a substance(s) that competitively inhibited the binding of aLDL to the macrophage scavenger receptor. The possibility exists that larger amounts of these substances could also interfere with the interaction of platelets and macrophages and result in inhibition of platelet-induced CE accumulation. However, preliminary experiments aimed directly at the role of macrophage lipoprotein receptors, including both the LDL receptor and the scavenger receptor, have not implicated either receptor in platelet-induced $\mathrm{CE}$ accumulation. The inclusion of heparin, dextran sulfate, fucoidin, and polyinosinic acid either separately or in combination at concentrations at which they have been demonstrated to prevent either LDL receptor or scavenger receptor binding (27) did not interfere with platelet-induced increases in cholesterol esterification, suggesting that these receptors are not involved. However, further studies are necessary to completely rule out the lipoprotein receptors and to identify the cause of the decline in activity observed with high platelet numbers.

What is the implication of this in vitro phenomenon for the pathogenesis of atherosclerosis and foam cell formation in vivo? Evidence that progression of an atherosclerotic lesion is related to the integrity of platelet function comes from multiple sources. Harker and colleagues (28) induced vessel wall intimal lesions with homocysteine in baboons and showed that dipyridamole, an agent that inhibits platelet reactions, was able to inhibit the proliferative response and prevent the formation of lesions. Moore et al. (29) induced thrombocytopenia in rabbits and demonstrated that in the absence of circulating platelets no lesions developed in response to physical injury of the vessel wall. Von Willebrand factor is required for platelet adhesion, and hypercholesterolemic pigs with homozygous deficiency of this factor have been reported to develop fewer lesions than normal pigs fed the same high cholesterol diet (30). More recently, aspirin therapy has been shown to decrease both macroscopic and microscopic experimental atherosclerosis in dogs (31).

Morphologic studies by Gerrity (1) and Faggiotto and Ross $(2,3)$ to track the development of lesions of atherosclerosis resulting from hypercholesterolemia in swine and in nonhuman primates suggests that after adherence and subendothelial migration of blood-derived monocytes, changes in the luminal surface of the artery lead to the loss of endothelial cells. A striking feature of this more advanced proliferative lesion is the presence of large numbers of spread platelets or platelet micro-particles adhering to the subendothelium, and particularly those in intimate and close contact with macrophages. After exposure of the subendothelium, a series of events take place including adhesion and aggregation of platelets and platelet granule secretion. These series of events mobilize monocyte-derived macrophages, which then ingest the cholesterol-bearing platelet debris. Platelet antigens are easily detected in the foam cells of atherosclerotic lesions (4). Such a close association between activated platelets containing large amounts of free cholesterol and monocytes could lead to massive $\mathrm{CE}$ accumulation and perpetuation of endothelial cell damage and progression of an atherosclerotic lesion. Thus, we hypothesize that platelets enhance foam cell formation after damage to the endothelium, and thus can contribute to progression of the fatty streak lesion.

\section{Acknowledgments}

We wish to thank Dr. Dan Steinberg for his thoughtful discussion, Vicky Byers-Ward, Susan Harrison, and Kathi Richards for technical help, and Joy Lozano for preparing the manuscript.

This work was supported in part by National Institutes of Health grants HL-35297, HL-14197, and RR-00833. L. K. Curtiss is an Established Investigator of the American Heart Association.

\section{References}

1. Gerrity, R. G. 1981. The role of the monocyte in atherogenesis. I. Transition of blood-borne monocytes into foam cells in fatty lesions. Am. J. Pathol. 103:181-190.

2. Faggiotto, A., R. Ross, and L. Harker. 1984. Studies of hypercholesterolemia in the nonhuman primate. I. Changes that lead to fatty streak formation. Arteriosclerosis. 4:323-340.

3. Faggiotto, A., and R. Ross. 1984. Studies of hypercholesterolemia in the nonhuman primate. II. Fatty streak conversion to fibrous plaque. Arteriosclerosis. 4:341-356.

4. Sevitt, S. 1986. Platelets and foam cells in the evolution of atherosclerosis. Histological and immunohistological studies of human lesions. Atherosclerosis. 61:107-115.

5. Chandler, A. B., and R. A. Hand. 1961. Phagocytized platelets: a source of lipids in human thrombi and atherosclerotic plaques. Science (Wash. DC). 134:946-947.

6. Kruth, H. S. 1985. Platelet-mediated cholesterol accumulation in cultured aortic smooth muscle cells. Science (Wash. DC). 227:12431245.

7. Mendelsohn, M., and I. Loscalzo. 1985. Activated platelets are a potent source of cholesterol for macrophage foam cell formation. Blood 66:309a. (Abstr.)

8. Curtiss, L. K., and T. S. Edgington. 1982. Immunochemical heterogeneity of human plasma apolipoprotein B. I. Apolipoprotein B binding of mouse hybridoma antibodies. J. Biol. Chem. 257:1521315221 . 
9. Markwell, M. A. K., S, M. Haas, L. L. Bieber, and N. E. Tolbert. 1978. A modification of the Lowry procedure to simplify protein determination in membrane and lipoprotein samples. Anal. Biochem. 87: 206-210.

10. Gamble, W., M. Vaughan, H. S. Kruth, and J. Avigan. 1978. Procedure for determination of free and total cholesterol in micro- or nanogram amounts suitable for studies with cultured cells. J. Lipid Res. 19:1068-1070.

11. Heider, J. G., and R. L. Boyett. 1978. The picomole determination of free and total cholesterol in cells in culture. J. Lipid Res. 19:514-518.

12. Basu, S. K., M. S. Brown, Y. K. Ho, R. J. Havel, and J. L. Goldstein. 1981. Mouse macrophages synthesize and secrete a protein resembling apolipoprotein E. Proc. Natl. Acad. Sci. USA. 78:7545-7549.

13. Steinbrecher, U. P., M. Fisher, J. L. Witztum, and L. K. Curtiss. 1984. Immunogenicity of homologous low density lipoprotein after methylation, ethylation, acetylation or carbamylation: generation of antibodies specific for derivatized lysine. J. Lipid Res. 25:1109-1116.

14. Curtiss, L. K., and E. F. Plow. 1984. Interaction of plasma lipoproteins with human platelets. Blood. 64:365-374.

15. Plow, E. F., and M. H. Ginsberg. 1981. Specific and saturable binding of plasma fibronectin to thrombin-stimulated platelets. J. Biol. Chem. 256:9477-9482.

16. Tsao, B. P., D. S. Fair, L. K. Curtiss, and T. S. Edgington. 1984. Monocytes can be induced by LPS-triggered T lymphocytes to express functional Factor VII/VIIa protease activity. J. Exp. Med. 159:10421057.

17. Curtiss, L. K. 1985. Application of monoclonal antibodies to issues of plasma lipoprotein structure and function. In Hybridoma Technology in the Biosciences and Medicine. T. S. Springer, editor. Plenum Publishing Corp., New York. 291-308.

18. Pepe, M. G., and L. K. Curtiss. 1986. Apolipoprotein E is a biologically active constituent of the normal immunoregulatory lipoprotein, LDL. J. Immunol. 136:3716-3723.

19. Kaiuzny, M. A., L. A. Duncan, M. V. Merritt, and D. E. Epps. 1985. Rapid separation of lipid classes in high yield and purity using bonded phase columns. J. Lipid Res. 26:135-140.

20. Labarca, C., and K. Paigen. 1980. A simple, rapid, and sensitive DNA assay procedure. Anal. Biochem. 102:344-352.
21. Basu, S. K., Y. K. Ho, M. S. Brown, D. W. Bilheimer, R. G. W. Anderson, and J. L. Goldstein. 1982. Biochemical and genetic studies of the apoprotein $\mathrm{E}$ secreted by mouse macrophages and human monocytes. J. Biol. Chem. 257:9788-9795.

22. Kayden, H. J., F. Maschio, and M. G. Traber. 1985. The secretion of apolipoprotein E by human monocyte-derived macrophages. Arch. Biochem. Biophys. 239:388-395.

23. Brown, M. S., J. L. Goldstein, M. Krieger, Y. K. Ho, and R. G. Anderson. 1979. Reversible accumulation of cholesteryl esters in macrophages incubated with acetylated lipoproteins. J. Cell. Biol. 82:597613.

24. Werb, Z., and J. R. Chin. 1983. Endotoxin suppresses expression of apoprotein $\mathrm{E}$ by mouse macrophages in vivo and in culture. J. Biol. Chem. 258:10642-10648.

25. Jungi, T. W., M. O. Spycher, U. E. Nydegger, and S. Barandun. 1986. Platelet-leukocyte interaction: selective binding of thrombin-stimulated platelets to human monocytes, polymorphonuclear leukocytes, and related cell lines. Blood. 67:629-636.

26. Phillips, D. R., K. Arnold, and T. L. Innerarity. 1985. Platelet secretory products inhibit lipoprotein metabolism in macrophages. Nature (Lond.). 316:746-747.

27. Basu, S. K., M. S. Brown, Y. K. Ho, and I. C. Goldstein. 1979. Degradation of low density lipoprotein electron sulfate complexes associated with deposition of cholesteryl esters in mouse macrophages. $J$. Biol. Chem. 254:7141-7146.

28. Harker, L., R. Ross, S. Slichter, and C. Scott. 1976. Homocystineinduced arteriosclerosis: the role of endothelial cell injury and platelet response in its genesis. J. Clin. Invest. 58:731-741.

29. Moore, S., R. J. Friedman, D. P. Singal, J. Gauldie, and M. Blajchman. 1976. Inhibition of injury-induced thromboatherosclerotic lesions by antiplatelet serum in rabbits. Thromb. Diath. Haemorrh. 35: 70-81.

30. Fuster, V., E. J. W. Bowie, J. C. Lewis, D. N. Fass, C. A. J. Owen, and A. C. Brown. 1978. Resistance to arteriosclerosis in pigs with von Willebrand's disease. J. Clin. Invest. 61:722-730.

31. Chesebro, J. H., V. Fuster, and L. R. Elvebock. 1984. Effect of depyridamole and aspirin on late vein-graft patency after coronary bypass operations. N. Engl. J. Med. 310:209-214. 